\title{
Restoring Washed Out Bridges so ELearners Arrive at Online Course Destinations Successfully
}

\author{
Ruth Gannon Cook \\ School for New Learning, DePaul University, Chicago, USA \\ Email: rgannonc@depaul.edu
}

Received March 5 ${ }^{\text {th }}$, 2012; revised April $8^{\text {th }}$, 2012; accepted April 29 $9^{\text {th }}, 2012$

\begin{abstract}
This study researched the impact of strategic navigation improvements in an online course selected for the study over one quarter (12 weeks) at a large Midwestern private university. The primary purpose of the study was to see if navigation enhancements and specific graphic enhancements (semiotic tools) in the online course selected for the study could make it easier for adult students to learn new course materials. The study also sought to see if these factors could contribute to increased positive learning experiences and to see whether there might be a higher percentage of completion rates in this enhanced online course than in other online courses at the university. While not generalizable, the findings could provide inferences about which factors could positively influence adult learning in online courses and contribute to increased course completion rates; the study could also provide recommendations on graphic enhancements and online course navigation that positively influence student learning in online courses.
\end{abstract}

Keywords: ELearning; Online Learning; Semiotics; Graphic Enhancements; Principal Components Analysis; Development Design; Adult Learners; Higher Education; Andragogy

\section{Description of Study}

This study investigated specific navigation enhancements and specific graphic enhancements (semiotic tools) in one online undergraduate course to see whether students could grasp course materials and assignments more readily in the online course studied. In addition, the study sought to find whether students in the online study course had a higher course completion rate than the national averages (Nash, 2005) shown for online courses.

The initial investigation sought to look at whether specific graphic enhancements (semiotic tools) could have sufficient positive effects on students participating in the online course so as to demonstrate greater student satisfaction with the course and a higher completion rate than average online course completion rates in online courses.

For the purposes of this study some terms will be used interchangeably, online learning and elearning; other terms, such as distance education and Internet or web-based learning, are also exchanged throughout the research study.

\section{Review of Literature}

The focus of this study was initially to see whether graphic enhancements embedded strategically in one online course for adult learners at a large Midwestern private university could enlist and engage students sufficiently so as to help students feel more comfortable in the online course, reduce cognitive load to some degree for those students, and perhaps contribute to a higher course completion rate for students in that course. The researcher compared this online course with other home university online course completion rates, and compared the national statistics' online course completion rates to see if the strategically embedded graphics and media-enhancements (designed with implanted graphics, metaphors, and multimedia) had a more positive effect on adult learners in the course and, ultimately, also on learner retention. The researcher also reviewed literature on adult learners and cognitive load, and on semiotics, a topic seldom researched with respect to on-line courses and degree programs. The purpose was to see if specifically embedded graphic enhancements in the online course could make it easier for students to learn new course materials and master the course competencies listed as desired course deliverables (outcomes). The researcher also sought to see if those factors, such as the strategically-embedded graphic enhancements, could also contribute to increased course completion rates for students enrolled in the online course of the study.

The literature review also looked at online best practices, and motivational theory related to student retention. While the review also included factors, such as attrition, work, family responsibilities, financial stresses, and self-regulation, the focus of the study was on online learning, course navigation and course tools factored into the cognitive load of students in those courses.

\section{Adult Learners and Cognitive Load}

\section{Adult Learners}

Several studies (Bradburn, Berger, Li, Peter, \& Rooney, 2005; Hudson \& Shafer, 2005) of students enrolled in undergraduate programs found that while a majority of undergraduates in traditional degree programs were younger than 24 , one in four students was actually 30 or older. About 43 percent of undergraduates enrolled in postsecondary education in the United States were age 24 or older (National Center for Education Statistics, 2007). At least 36 percent of postsecondary students were age 25 or older and 47 percent were independent students (Center for Postsecondary and Economic Success, 2011). (The students in participating in this study were at least 24 years of 
age (University data, 2012).

\section{Cognitive Load}

Cognitive load theory (Sweller, 1988, 1994) is an instructional theory... (that) describes learning structures in terms of an information processing system involving long term memory, which effectively stores all of our knowledge and skills on a more-or-less permanent basis and working memory, which performs the intellectual tasks associated wsith consciousness. Information may only be stored in long term memory after first being attended to, and processed by, working memory. Working memory, however, is extremely limited in both capacity and duration... The fundamental tenet of cognitive load theory is that the quality of instructional design will be raised if greater consideration is given to the role and limitations, of working memory (Cooper, 1998: p. 1).

Cognitive load is a term that was first used by John Sweller to describe the amount of pressure related to the mind and its working memory (WM) (Sweller, 1988, 1994). The theory associated with cognitive load contends that the more stress, activities, and information are added to a person's short term memory, the more that person has difficulty processing and retaining the information and becomes overwhelmed by too much information. There are varying numbers as to how much information becomes too much, before overload. There seems to be a general consensus of around seven pieces or chunks of information that the mind can retain before a mind begins to feel overloaded and begins to experience greater stress (Miller, 1956).

Several types of cognitive load have come to be identified: Intrinsic cognitive load, which was first used by Chandler and Sweller (1991) and was described as being the inherent difficulty of learning material that is integral to the material that may not be altered or changed (by an instructor, parent, leader, etc.). Extraneous cognitive load is external information presented to individuals which is controlled by the parties delivering that information. In education it would be the curricula designers, teachers, instructional designers, and administrators. Because extraneous cognitive load usually consists of specific limited cognitive resources, learning materials can be designed to reduce the extraneous load with restrictions on the volume of information provided in those materials. Germane cognitive load is that aspect of cognitive load that relates to the "processing, construction and automation of schemas," (Wikipedia, 2012, Cognitive Load). Schemas, as described in the definition of germane cognitive load, are thought patterns, or mental knowledge frameworks, usually with specific themes that organize social information (2012, Schemas); schemas provide structures to organize and help facilitate interpreting and processing information.

Schemas can contribute to the enhancement or impediment of learning. Chandler and Sweller (1991) pointed out that the format of instructional materials could also either promote or limit learning, therefore differences in learning (and performance) could be due to higher levels of cognitive load. So, dependent upon the format of instruction, students could learn effectively... or fail to learn. Chandler and Sweller termed this "extraneous cognitive load" (p. 235) to describe factors outside the teacher and student that introduce artificially induced cognitive load, so, in online learning, extraneous factors could include not only the online course content, but the instructional design, the course navigation, and the learning management system of each course. So techniques can be applied to manage complexity in online courses by segmenting and sequencing complex materials, and instructional designers can limit extraneous load and promote germane load (Paas, 2004).

People learn better when they can scaffold new knowledge on existing schemas, what they already understand (Vygotsky, 1962, 1978, 1981; Wertsch, 1985). But the more a person has to learn in a shorter amount of time, the more difficult it is to process that information in working memory. Cognitive overload is often difficult to identify in students, particularly online students, because they generally cannot be directly observed in an online course, unless the course is taught in a synchronous environment. Students can usually be monitored solely by the instructor auditing their participation in online course discussions and other interactivities, by assessing their homework assignments, by evaluating their emails and interactions with the instructor, and, ultimately, by the students' successful (or unsuccessful) completion of the course. The researcher felt it was critical to review cognitive load and its' effects on students in online courses, so that factors that produced student overload might be identified, and factors that had positive effects on student learning could also be identified.

\section{Semiotics and Graphic Enhancements}

Semiotics is the study of patterned human communication behavior, including: auditory/vocabulary, including writing and narratives; language; numerical figures; proxemics, such as facial expressions, touch, and artificial limb extensions; metaphors, signs, and symbols (Merriam-Webster, 2009).

Earlier research revealed that learning occurred through a continual interplay between cognitive and affective factors (Gannon-Cook, 1998; Gannon-Cook \& Crawford, 2007; Pintrich, Marx, \& Boyle, 1993); research also brought to light that students who were successful in their studies attributed partial success to structured narration that consisted of story structure and schema which could include semiotic elements (Mandl et al., 1984).

But semiotic elements, such as signs, metaphors, and narratives may have multiple meanings, so there would need to be careful study of which signs, symbols, etc., to choose in each online course design in order to include semiotic elements that were generic enough to have almost universal recognition. (Examples of universal symbols could be a boat sailing on water to represent navigation, a family having dinner talking and eating around a table, people sitting around a campfire, hikers with backpacks walking down a hiking trail, a mother or family playing with children, etc.).

Students' cultural and historical recognition patterns varied significantly, depending on many factors: locale, cultural and family traditions, socioeconomics, educational experiences, and learning styles; and students could also be affected by the omission of any of these factors because the absence of any factor could result in a lack of a connection or bridge to prior knowledge that created a virtual diaspora (Gannon-Cook, 2007, 2008; Popkewitz, 1997, 1998, 2004). This lack of bridging to prior knowledge could present greater challenges for online students since they must jump directly into new course materials, as well as learn the online technology, the learning management system, and the course navigation. "The immersion of students into new content material establishes new patterns of 
exclusion that perpetuate an unequal educational playing” (Popkewitz, 1997: p. 27).

Semiotics, when included in the design of online courses, could have implications as far as learner retention because these symbolic representations, when strategically embedded into online courses, could resonate with students by providing subliminally recognizable symbols that bridge to their prior knowledge and cultural experiences. If specifically embedded graphic enhancements could make it easier for students to learn new course materials, it would be worth including these semiotic elements because these additions could also contribute to better understanding of course materials and lead to increased student understanding. Ultimately it could also contribute to increased course completion rates for students enrolled in the course of the study.

One of the findings uncovered in the research is students' constructions of knowledge that are based on their participation (or lack of participation) in historically derived systems of reasoning that are not included in online course templates or content materials (Popkewitz, 1997). Since online courses usually focus solely on the specified content material, there could be risks for students that need some of that undergirding of historical or representational meaning; students could actually add to their cognitive load by feeling overwhelmed with a sense of something missing, even as they are still exposed to all of the new materials and activities in the online courses.

Ironically, most online courses are still highly text-based; these courses are still mediated in the same ways, so there is a need to return to an inclusion of historical and semiotic artifacts as social forces to assist students, particularly those returning to school, at-risk, or developmentally challenged, to feeling more comfortable with the new knowledge on a deeper, metalinguistic level. Popkewitz (1997) points out that “The eye doesn't just see but is socially disciplined in the ordering, dividing, making of the possibilities of the world and self” (p. 20).

Lashley (1951), argued that (learning) materials appear to generally be organized in linear and flat fashion, but this format also conceals an underlying hierarchical structure. Thus sequences can consist of sub-sequences and these can in turn consist of sub-sub-sequences. While linear representation and sequencing is simple from storage point of view, there can be potential problems during retrieval. For instance, if there is a break in the sequence chain, something missing, subsequent elements become inaccessible. Sakai et al. (2003) showed that subjects spontaneously organize information into a sequence chain, then into a number of chunks across a few sets; he also showed that performance was poorer when the sequencing chunks were disrupted or random.

Note: In Figure 1 there are at least nine online course activities shown here that students must use; they may approach these one at a time, or they may become subsequently more frustrated and become cognitively overloaded as they try to perform each activity (If, as research has indicated, it only takes approximately seven pieces of information or activity and cognitive overload sets in, students could be entering cognitive overload from the very beginning of an online course).

If students are introduced to the new online course with a "bridge" of information that contains recognizable symbols, metaphors, or narratives to remind them of their knowledge base, then they have a passage that may help them feel more comfortable with taking on new knowledge and experiences because they can scaffold these onto their own experiences they've carried with them into the course.

Cooper (1998) gives an example of the challenges students face when having to integrate multiple sources of mental and sensory input in learning environments; other studies concur that students can feel bombarded with too much information and requirements, particularly in new educational settings (Ambron \& Hooper, 1990). In online courses, students not only need to learn the new course materials, but also have to know or learn how to use the technology in order to navigate the course effectively. Couple all of this with the processes related to higher-order thinking, such as problem-solving, knowledge transfer, and the complexities of learning, and a multiplier effect occurs that can exacerbate the effects of all these concurrent activities on learners. At this point an online task with two or three simple steps could then cause frustration and negative reactions for a learner with cognitive over-load caused by the complex skills required for taking those steps (Cooper, 1998; Pavio, 1990; Baddeley, 1992).

In the online learning environment "the social is presented as a psychological or symbolic interactional process of negotiations

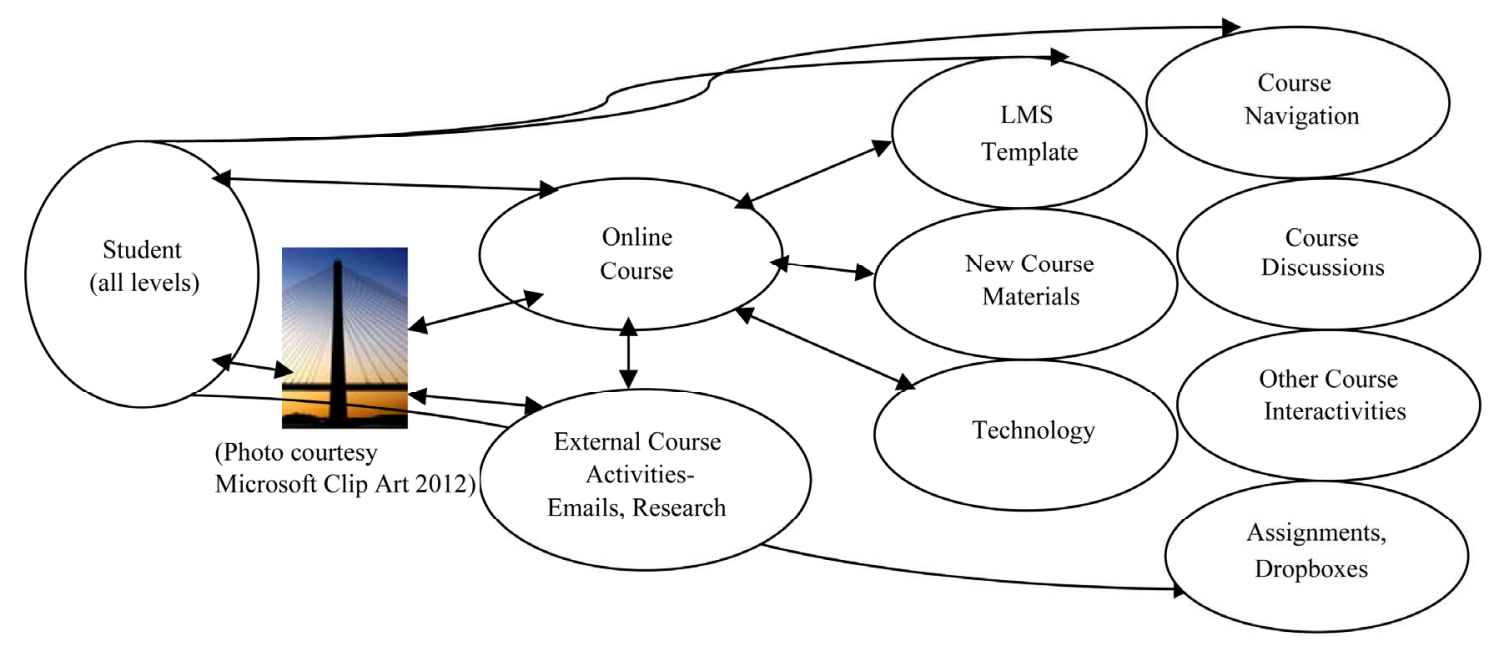

Figure 1.

Cognitive load activities for students in online courses. 
to construct knowledge... but (one) which strips (away)... any social mooring outside the classroom In the case of online learning, the exclusions consist of semiotic tools and sociocultural influences from the world outside the course. "For example, how the concepts and methods of science, social science and literature are embedded in historical relations and power structures is not studied." (Popkewitz, 1998: p. 551).

Since college dropout rates are consistently higher for minority and underserved students (National Center for Educational Statistics, 2008), there could be a correlation between the absence of cultural and historical anchors and academic underperformance, so it is important to take a look at finding a way to introduce tools, such as signs, metaphors, narratives, that help the learner reinforce her or his cultural and historical anchors. It would be sad to learn that something as simple as introducing graphics and metaphors to reinforce students' comfort zones could help them enter the online course more ready for the challenges of the course and more prepared to complete the course.

\section{Analysis of Data}

The researcher conducted a research study to see if there could be a positive impact on students in online courses with strategic navigation improvements, both in the course, and in increased student course completion rates. The researcher used a mixed methods methodology, first using quantitative research to collect data from an electronic survey sent out to students enrolled in both the graphically enhanced course and twentyfour other online courses. The researcher then collected the data into a Principal Components Analysis (PCA) to distill which factors could have a positive impact on the online learners. Then the research utilized a qualitative methodology, using development design to assess whether the graphic enhancements, or other innovations, could improve students' performance in the online course.

The study was conducted over one quarter (11 weeks) at a large Midwestern private university. The primary purpose of the study was to see if navigation enhancements and specific graphic enhancements (semiotic tools) in the online course selected for the study could make it easier for students to learn new course materials; the researcher would also look at the final course completion rates to see if the completion rates may be higher with students who had taken the graphically enhanced course.

The sample population for this study was adult learners (students at least 24 years of age).

After receiving permission to administer the survey, it was pretested in the summer of 2007 with 25 student participants (see Appendix A). In the fall of 2007 it was sent out to students in half of the courses (25) offered by the online university program with enrollments ranging from 12 to 20 students in each course, including one course designed with semiotic enhancements (25 students). Of the approximate 500 students sent the email request, 149 students participated in the survey, $30 \%$ of the potential respondents.

After collection of the raw data, tests were then conducted to validate the survey data in the early winter 2008 quarter (Tabachnick \& Fidell, 2001). Issues, such as sample adequacy, missing data, data set fit to methodology were addressed; the methodologies utilized in the study included both quantitative and qualitative research.
The study summarized the descriptive data and provided a detailed analysis of the twenty-three Likert-scale questions ranging from 1 (strongly disagree) to 5 (strongly agree). The questions were coded with an identifying code for each question (variable) and analyzed to see if there were any correlations among the variables.

\section{Principal Components Analysis (PCA)}

The data was then analyzed using a principal components analysis (PCA), the statistical technique that derives the probable number and nature of the survey factors (Merenda, 1997). The PCA combined the variables into groups (factors) which "reflected (the) underlying processes that have created the correlations among variables” (Tabachnick \& Fidell, 2001: p. 582). The factors were distilled to arrive at a new set of fewer variables from which inferences could be made (Cabrera, 1994; Colbeck, Cabrera, \& Marine, 2002). A Cronbach alpha, used when items on a measure are not scored dichotomously (Gall, Borg \& Gall, 1996; Wiersma \& Jurs, 1990), computed test score reliability with an estimate of internal consistency of greater than .70 alpha levels (Shiarella, Harris, McCarthy \& Tucker, 2000).

While the PCA is designed to reduce a large number of variables to a smaller number of variables (McDonald, 1985; Tabachnik \& Fidell, 2001); the PCA works with a smaller set of new criterion variables (Stevens, 1996), capturing all of the data in a few vectors (Houle, Mezey, \& Galpern, 2001). The original 16 survey questions (components) were reduced to six factors, only four of which met the criterion for meaningful correlations (.32). These accounted for $65 \%$ of the variance: Instructor Interaction (Factor 3), .92; Graphics, Podcasts, \& Phone Conferences (Factor 2), .85; Navigation and Explanations (Factor 1), .78; and Learning Styles (Factor 4), 70 (Appendix B).

Students had taken the time to respond to the survey and many had written responses in the open-ended questions, so it was important to look at these factors to see which elicited the strongest student responses because these could provide insights into which factors induced more student stress and which ameliorated it. Factor 1, Instructor Interaction, spoke to the need for students to feel their voices were heard by the instructor and university, also that their questions and concerns were addressed expeditiously. The next factor, Factor 2, including graphics to bridge cultural knowledge (which also included voice over Internet protocols, such as Skype, and podcasts), students ranked highly because they seemed to feel that the graphics and semiotic tools helped them to better connect with the instructor, other students, and with the new content materials. Factor 3, Navigation and Explanations, could assist the students to become more comfortable with finding materials and navigating through the courses with consistency to help minimize the anxiety and stress of not locating strategic course items. Last, Factor 4, Learning Style Factors, could be addressed more comprehensively so that instructional designers could address and implement measures to help students with activities and features that included their learning styles.

There were three open-ended questions, Questions 22, 17 and 23 that allowed students to discuss their feelings and needs which were not included in the PCA. Question 17 asked the question, Are there any other thoughts that you would like to share about your on-line learning experiences? Here are some 
of the 91 responses (58 either did not respond or said "no"): 31 responded they were happy with their online learning (10 of these did add other comments, such as, "would like more hybrid courses", "would like more timely responses from instructors", and "would like more interactivities with and control by instructor". Interestingly, only three students mentioned they would like more graphics and student aids in their courses, and only one student commented that (s)he would not take any more online courses or continue with the program. Question 22, What Do You Like or not like about Online Courses?, posed the answers "Freedom to Learn at my own pace, Time savings, Online courses are easier, and, Other" which allowed students to respond with three answers or add their own. One hundred thirty-two students responded they liked the freedom to learn at their own pace, eight liked the time savings, five thought online courses were easier (which did not identify whether easier meant more convenient or easier learning materials), two did not respond, and only two responded that online courses were less stressful.

Question 23 asked "If you have any other comments to share, such as one of the comments below, please do so here.” (The survey question also posted some suggested responses, see Table 1):

23. Do you have any other comments to share, if so, please do so here (the survey question also posted some suggested responses, see below):

a) It is up to my own determination to complete the course

b) More online chats and interactivities

c) More online study aids more help from instructor

Only ten students did not respond to the open-ended question 23; the fact that 139 students felt it important enough to respond made a statement that they did want their thoughts to be "heard" or represented. Eighty-seven felt they were pressing forward with their degree progress through their own efforts, another 20 felt they could use the help of additional graphics and study aids, eighteen wanted more interaction from their instructors, and 14 wanted more podcasts, Skype or phone conferences.

\section{Development Design Research}

The qualitative methodology utilized in the study was a developmental research design (Richey \& Klein, 2007). "Design and development research seeks to create knowledge grounded in data systematically derived from practice” (Richey \& Klein, 2007: p. 1). The primary method utilized was a content analysis of the survey data with an in-depth review of the open-ended survey questions. The researcher identified contextual factors and existing philosophies, and conditions that enhanced or inhibited the questions used in the survey, including any noted in

Table 1.

Question 23 student responses.

\begin{tabular}{lc}
\hline Study aids and graphics & 20 \\
More help from instructor & 18 \\
More chats and interactivities & 14 \\
(Succeed) Through my own determination & 87 \\
Blanks (no response) & 10 \\
Total & 149 \\
\hline
\end{tabular}

the students' open-ended responses (Forsyth, 1998; Richey \& Klein, 2007). The research was designed to look at the "impact of the many factors that exist in the natural workplace (environment), factors that are eliminated in most laboratory research... which give(s) design and development researchers the opportunity to draw conclusions based upon a dataset that is not only realistic, but (is) also isolated from irrelevant details” (p. 80). The researcher's observations supported the findings of the quantitative survey in several key areas: first, that students seemed to be more interested in interaction with the instructor and desirous of meaningful feedback, not just "good job" or "receipt acknowledged"; despite so many students having exposure to using personal email and texting, even technologically sophisticated students seemed confused and frustrated by inconsistent information and formatting in their online courses; some students indicated they would very much like more graphics and pictorial representations, such as screen captures and visual aids.

The development design research included a review of some of the courses in the survey so that the researcher could search for elements that could positively affect or potentially frustrate students in virtual environments, as well as a search for elements that could include aspects of students' cultural environments. These aspects would not be observable in the survey data, so the researcher looked at whether the instructional designers had included semiotic and sociocultural elements that might be embedded in the actual courses being studied.

Design and development theory "can be informed by contextualized findings as well as those generated by data derived from traditional sampling techniques” (Richey \& Klein, 2007: p. 130). This type of data can provide important insights, such as the large number of respondents who took the time to voice their thoughts about questions raised in the survey, and did so in the discussion threads of the courses as well as in the openended survey questions. The findings suggested that the human need for approval and to be heard were very much present in these students' minds, even more so than just their expressed desires for quick response time or for more technologies, although some did indicate they would like more podcasts and Skype sessions.

\section{Summary}

In summary, the study researched adult-learner cognitive load in online courses and compared text-based online courses (traditional courses transferred to online formats that do not contain graphics, metaphors, or multimedia) and graphics and media-enhanced online courses with embedded graphics, metaphors, or multimedia (Cobley, 1997) to see which had a more positive effect on adult-learner cognitive load and, whether this load could affect learner retention. The variables found to best predict how to regulate cognitive load and reduce attrition were recommended for inclusion in future instructional online course designs at the Midwestern private university. While the study was too small to be generalizable, the findings could still provide valuable insights into which factors could reduce student cognitive load, reinforce student retention in online courses, and contribute to the body of knowledge on elearning in postsecondary education.

\section{REFERENCES}

Ambron, S., \& Hooper, K. (Eds.) (1990). Learning with interactive 
multimedia: Developing and using tools in education. Washington: Microsoft Press.

Baddeley, A. D. (1992). Working memory. Science, 255, 556-559. doi:10.1126/science.1736359

Berker, A., \& Horn, L. (2005). Work first, study second: Adult undergraduates who combine employment and postsecondary enrollment. The Education Statistics Quarterly, 5, 2004.

Bradburn, E., Berger, R., Li, X. Peter, K., \& Rooney, K. (2004). A Descriptive summary of 1999-2000 bachelor's degree recipients 1 year later: With an analysis of time to degree. The Education Statistics Quarterly, 5.

Cabrera, A. (1994). Logistic regression analysis in higher education: An applied perspective. In J. C. Smart (Ed.), Higher education: Handbook of theory and research (pp. 225-256). New York: Agathon Press.

Center for Law and Social Policy (2011). Statistics on nontraditional learners. URL.

http://www.clasp.org/admin/site/publications/files/Nontraditional-Stu dents-Facts-2011.pdf

Chandler, P., \& Sweller, J. (1991). Cognitive load theory and the format of instruction. Cognition and Instruction, 8, 293-332. doi:10.1207/s1532690xci0804_2

Chang, S. (2006). Online versus print reading: A cognitive load perspective. Association for Education Communications and Technology, Dallas, October 2006.

Cobley, P., \& Jancz, L. (1997). Introducing semiotics. Royston: Icon Books.

Colbeck, C., Cabrera, A., \& Marine, R. (2002). Faculty motivation to use alternative teaching methods. The Annual Meeting of the American Educational Research Association, New Orleans, April 2002.

Cooper, G., (1998). Research into cognitive load theory and instructtional design at University of New South Wales (UNSW). URL (last checked 1 December 2006).

http://projects.ict.usc.edu/itw/materials/clark/UNSW.htm

Forsyth, J. E. (1998). The construction and validation of a model for the design of community-based train-the-trainer instruction. Ph.D. Thesis, Detroit, MI: Wayne State University.

Gall, M. D., Borg, W. R., \& Gall, J. P. (1996). Educational research. (60th ed.). White Plains, NY: Longman.

Gannon-Cook, R. (1998). Semiotics in technology, learning and culture. Bulletin of Science, Technology \& Society, 18, 174-179. doi:10.1177/027046769801800304

Gannon-Cook, R. (2008). Web 2.0: How signs, symbols and podcasts affect elearning. In T. Kidd, \& I. Chen (Eds.), Wired for learning: An educator's guide to Web 2.0. Charlotte, NC: InfoAge Publishing.

Gannon-Cook, R., \& Crawford, C. (2007). What can cave walls teach us? In A. Edmondso, (Ed.), Globalized E-Learning Cultural Challenges. Minneapolis, MN: eWorld Learning.

Gobet, F., Lane, P. C. R., Croker, S., Cheng, P. C. H., Jones, G., Oliver, I., \& Pine, J. M. (2001). Chunking mechanisms in human learning. Trends in Cognitive Sciences, 5, 236-243. doi:10.1016/S1364-6613(00)01662-4

Houle, D. Mezey, J., \& Galpern, P. (2001). Interpretation of the results of common principal components analyses. Evolution, 56, 433-440.

Hudson, L., \& Shafer, L. (2005). Undergraduate enrollments in academic, career, and vocational education. The Education Statistics Quarterly, 6.

Lashley, K. S. (1951). The problem of serial order in behavior. In L. A. Jeffress (Ed.), Cerebral mechanisms in behavior. New York: Wiley.

Mandl, H., Stein, N., \& Trabasso, T. (Eds.) (1984). Learning and comprehension of text. Hillsdale, NJ: Lawrence Erlbaum Associates.

Maybery, M. et al. (2001). Grouping of list items reflected in the timing of recall: implications for models of serial verbal memory. Journal of Memory and Language, 47, 360-385.

McDonald, R. (1985). Factor analysis and related methods. Hillsdale, NJ: Lawrence Erlbaum Associates Publishers.

Merenda, P. (1997). Methods, plainly speaking. A guide to the proper use of factor analysis in the conduct and reporting of research: Pitfalls to avoid. Measurement and Evaluation in Counseling and Development, 30, 156-164.

Merriam-Webster's Dictionary Online (2009). Definition of discourse.
URL (last checked 20 July 2009).

http://www.merriam-webster.com/dictionary/semiotics

Miller, G. A. (1956). The magical number deven, plus or minus two: Some limits on our capacity for processing information. Psychological Review, 63, 81-97. doi:10.1037/h0043158

Nash, R. (2005). Course completion rates among distance learners: Identifying possible methods to improve retention. Online Journal of Distance Learning Administration, 8. URL.

http://www.westga.edu/ distance/ojdla/winter84/nash84.htm

National Center for Education Statistics (NCES) (2002). A profile of participation in distance education: 1999-2000. URL (last checked 15 January 2002). http://www.nces.ed.gov/pubs02/

National Center for Educational Statistics (NCES) (2007). The condition of education 2006: Distance education by postsecondary faculty. Washington DC: Institute of Educational Science, National Center for Educational Statistics.

Paas, F., Renkel, A., \& Sweller, J. (2004). Cognitive load theory: Instructional implications of the interaction between information structures and cognitive architecture. Instructional Science, 32, 1-8. doi:10.1023/B:TRUC.0000021806.17516.d0

Pavio, A. (1990). Mental representations: A dual coding approach. New York: Oxford University Press.

Pintrich, P. R., Marx, R. W., \& Boyle, R. A. (1993). Beyond cold conceptual change: The role of motivational beliefs and classroom contextual factors in the process of conceptual change. Review of Educational Research, 63, 167-199.

Popkewitz, T. (1997). A changing terrain of knowledge and power: A social epistemology of educational research. Journal of Educational Research, 26, 18-29.

Popkewitz, S. D. (1998). Review of the effects of research and practice. Journal of Educational Research, 35, 535-570. doi:10.2307/1163459

Popkewitz, T. (2004). The alchemy of the Mathematics curriculum: Inscriptions and the fabrication of the child. American Educational Research Journal, 41, 3-34. doi:10.3102/00028312041001003

Richey, R., \& Klein, J. (2007). Design and development research. Mahwah, NJ: Lawrence Erlbaum Associates, Publishers.

Sakai, K., Kitaguchi, K., \& Hikosaka, O. (2003). Chunking during human visuomotor sequence learning. Experimental Brain Research, 152, 229-242. doi:10.1007/s00221-003-1548-8

Shiarella, A. H., McCarthy, A. M., \& Tucker, M. L. (2000). Development and construct validity of scores on the community service attitudes scale. Educational and Psychological Measurement, 60, 286-300. doi:10.1177/00131640021970510

Stevens, J. (1996). Applied multivariate statistics for the social sciences (3rd ed.). Mahwah, NJ: Lawrence Erlbaum Associates, Publishers.

Sweller, J. (1988). Cognitive load during problem solving: Effects on learning. Cognitive Science, 12, 257-285. doi:10.1207/s15516709 $\operatorname{cog} 12024$

Sweller, J. (1994). Cognitive load theory, learning difficulty and instructional design. Learning and Instruction, 4, 295-312. doi:10.1016/0959-4752(94)90003-5

Tabachnick, B., \& Fidell, L. S. (2001). Using multivariate statistics (4th ed.). New York: HarperCollins College Publishers.

University Data (2012). Adult student requisites. URL (last checked 23 February 2012).

http://www.depaul.edu/admission-and-aid/types-of-admission/Pages/ adult-transfer-student.aspx

Vygotsky, L. S. (1962). Thought and language. Cambridge, MA: MIT Press. doi:10.1037/11193-000

Vygotsky, L. S. (1978). Mind in society. Cambridge, MA: Harvard University Press.

Wertsch, J. V. (1985). Cultural, communication, and cognition: Vygotskian perspectives. Cambridge: Cambridge University Press.

Wiersma, W., \& Jurs, S. (1990). Educational measurement and testing. Needham Heights, MA: Allyn and Bacon.

Wikipedia (2012). Definition of chunking. URL (last checked 24 February 2012). http://en.wikipedia.org/wiki/Chunking_(psychology)

Wikipedia (2012). Definition of cognitive load. URL (last checked 23 February 2012). http://en.wikipedia.org/wiki/Cognitive_load

Wikipedia (2012). Definition of schemas. URL (last checked 23 February 2012). http://en.wikipedia.org/wiki/Schema_(psychology) 


\section{Appendix A}

Comparisons of Course without Graphic Enhancements versus With Graphic Enhancements Online Course in Learning Management Templates Without Graphic Enhancements:

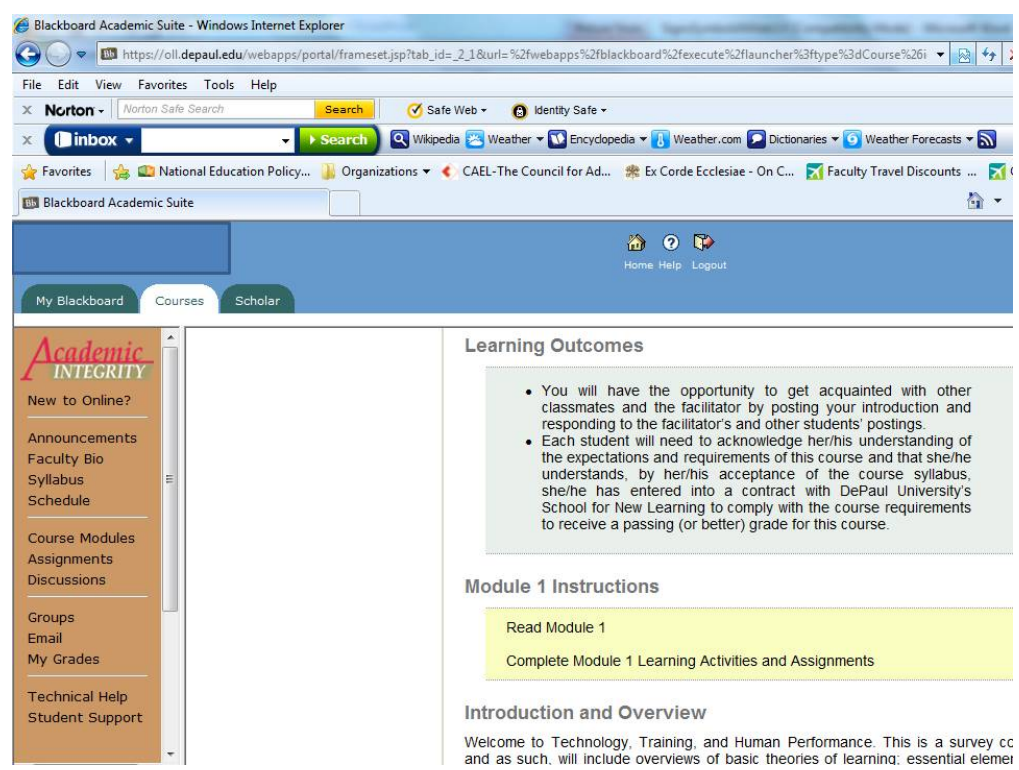

With Graphic Enhancements:
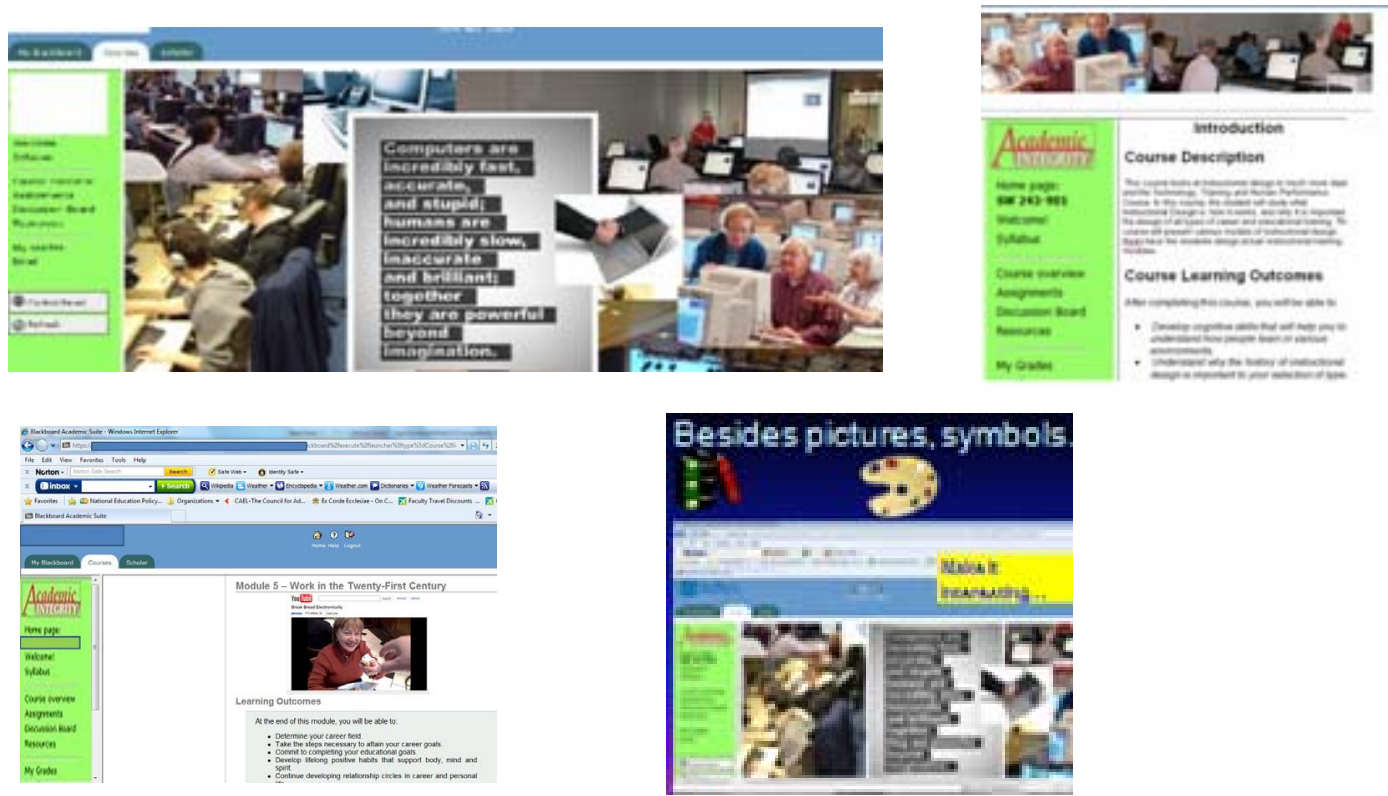
R. G. COOK

\section{Appendix B}

PCA Scree Plot

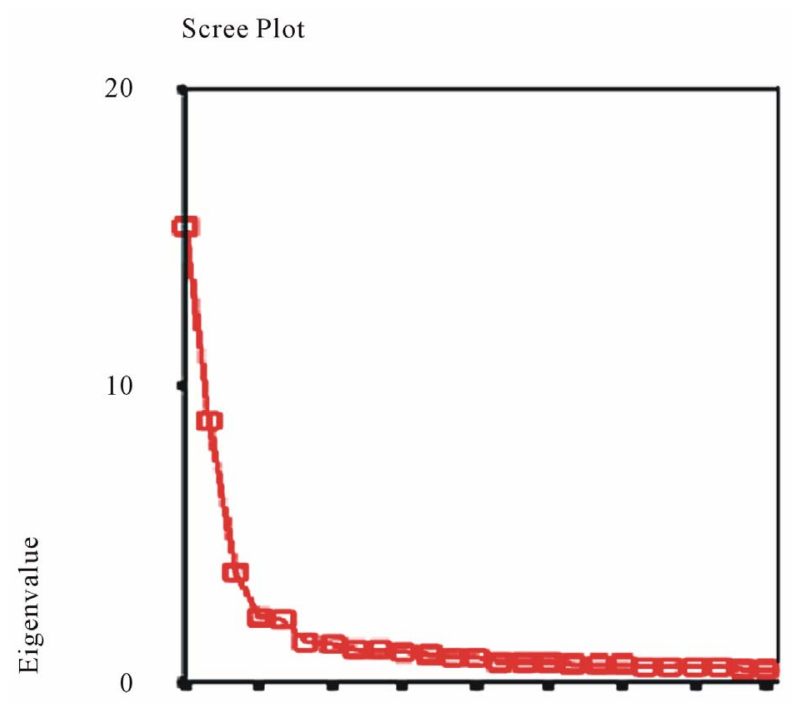

The first four factors accounted for $65 \%$ of the variance: Instructor Interaction (Factor 3) .92; Graphics, Podcasts, \& Phone Conferences (Factor 2), .85; Navigation and Explanations (Factor 1), .78; Learning Styles (Factor 4), .70; (Factor 5, Technology skills, and Factor 6, External Experiences, comprised; a combined 18\%, with Factors 7-10 comprising the remaining 17\% of the variance). 